\title{
Early predictors of chronic post-traumatic stress disorder in assault survivors
}

\author{
BIRGIT KLEIM ${ }^{1}$, ANKE EHLERS ${ }^{1 *}$ AND EDWARD GLUCKSMAN ${ }^{2}$ \\ ${ }^{1}$ Institute of Psychiatry, Department of Psychology, King's College London, London, UK; ${ }^{2}$ Accident and \\ Emergency Department, King's College Hospital London, London, UK
}

\begin{abstract}
Background. Some studies suggest that early psychological treatment is effective in preventing chronic post-traumatic stress disorder (PTSD), but it is as yet unclear how best to identify trauma survivors who need such intervention. This prospective longitudinal study investigated the prognostic validity of acute stress disorder (ASD), of variables derived from a meta-analysis of risk factors for PTSD, and of candidate cognitive and biological variables in predicting chronic PTSD following assault.
\end{abstract}

Method. Assault survivors who had been treated for their injuries at a metropolitan Accident and Emergency (A\&E) Department were assessed with structured clinical interviews to establish diagnoses of ASD at 2 weeks $(n=222)$ and PTSD at 6 months $(n=205)$ after the assault. Candidate predictors were assessed at 2 weeks.

Results. Most predictors significantly predicted PTSD status at follow-up. Multivariate logistic regressions showed that a set of four theory-derived cognitive variables predicted PTSD best (Nagelkerke $R^{2}=0 \cdot 50$ ), followed by the variables from the meta-analysis (Nagelkerke $R^{2}=0 \cdot 37$ ) and ASD (Nagelkerke $\left.R^{2}=0 \cdot 25\right)$. When all predictors were considered simultaneously, mental defeat, rumination and prior problems with anxiety or depression were chosen as the best combination of predictors (Nagelkerke $R^{2}=0 \cdot 47$ ).

Conclusion. Questionnaires measuring mental defeat, rumination and pre-trauma psychological problems may help to identify assault survivors at risk of chronic PTSD.

\section{INTRODUCTION}

After experiencing a violent traumatic event, such as an assault or terrorist attack, most people show some symptoms of distress, but only a minority develop persistent symptoms of sufficient severity to warrant a diagnosis of posttraumatic stress disorder (PTSD) (Galea et al. 2002; Rubin et al. 2005; Shalev \& Freedman, 2005). Most people recover from trauma without formal intervention (Kessler et al. 1995), and there is evidence that brief early interventions given to all trauma survivors do not

\footnotetext{
* Address for correspondence: Professor Anke Ehlers, Department of Psychology (PO77), Institute of Psychiatry, De Crespigny Park, London SE5 8AF, UK.

(Email: anke.ehlers@iop.kcl.ac.uk)
}

prevent chronic PTSD (for reviews, see NCCMH, 2005; Rose et al. 2002). However, early trauma-focused cognitive-behavioural treatment of trauma survivors with high levels of PTSD symptoms is effective (for recent reviews, see NCCMH, 2005; Bisson \& Cohen, 2006), and this treatment may be even more effective when delivered within the first weeks post-trauma than at later time points (Shalev et al. 2006). This has led to recommendations that early trauma-focused cognitive-behavioural treatment should be offered to trauma survivors with severe symptoms, and that screening should be considered for populations at risk of chronic PTSD (e.g. NCCMH, 2005).

This raises the question of how best to identify trauma survivors who are at risk of 
developing chronic PTSD and need intervention. One of the motivations for introducing the diagnosis of acute stress disorder (ASD) into DSM-IV (APA, 1994) was to help to identify, within the first weeks post-trauma, those individuals who are likely to go on to develop PTSD (Marshall et al. 1999). A range of empirical studies found indeed that the majority of trauma survivors with ASD go on to develop PTSD (e.g. Harvey \& Bryant, 1998; Brewin et al. 1999). However, several authors have recently questioned the predictive validity of the ASD diagnosis for subsequent PTSD, and have particularly challenged its sensitivity (McNally et al. 2003; Creamer et al. 2004). Studies with different trauma populations found that on average only $46 \%$ of those who developed PTSD had suffered from ASD in the initial month after trauma exposure (McNally et al. 2003); proportions ranged from $10 \%$ (severely injured accident survivors; Schnyder et al. 2001) to $72 \%$ (survivors of mild traumatic brain injury; Harvey \& Bryant, 2000). The low sensitivity poses a problem for clinical purposes as it may lead to a failure to identify individuals in need of treatment.

A review by Bryant (2003) concluded that psychological or biological reactions in the acute trauma phase may provide more accurate means of predicting PTSD than symptom-based measures such as the ASD diagnosis, but this hypothesis remains to be tested. The present paper explored the question of whether risk factors identified in previous research may help to improve the early identification of trauma survivors who are likely to develop PTSD.

The first set of predictors under consideration was based on a meta-analysis of risk factors for PTSD (Ozer et al. 2003). The meta-analysis identified seven variables as the best empirically established predictors of PTSD; most of these had also emerged as risk factors in an earlier meta-analysis (Brewin et al. 2000): peritraumatic dissociation (weighted effect size: $r=$ $0 \cdot 35$ ), perceived life threat during trauma, peritraumatic emotional responses (both $r$ 's $=0 \cdot 26$ ), history of trauma, history of psychological problems prior to the trauma, family history of psychopathology (all $r$ 's $=0 \cdot 17$ ), and post-trauma social support $(r=-0 \cdot 28)$. However, Ozer et al. (2003) used the term 'predictor' in a statistical sense and included many cross-sectional studies, some of which were conducted many years the trauma. It remains to be tested whether the risk factors identified in their metaanalysis consistently predict chronic PTSD when evaluated in a prospective longitudinal design.

The second set of candidate predictors was derived from a cognitive model of PTSD (Ehlers \& Clark, 2000). This model emphasizes factors that maintain PTSD in order to explain why some people develop persistent symptoms whereas others recover on their own. A series of prospective longitudinal studies showed that the cognitive factors specified in the model predict chronic PTSD at 6 months, 1 year and 3 years (Ehlers et al. 1998 b, 2003; Dunmore et al. 2001; Mayou et al. 2002; Murray et al. 2002; Halligan et al. 2003; Michael et al. 2005). The presumed maintaining factors also predicted PTSD severity at follow-up over and above what could be predicted from initial PTSD symptom severities. These include the candidate predictors chosen for the present study (with correlations with PTSD severity at 6 months to 1 year): mental defeat (Dunmore et al. 2001; $r=0 \cdot 64$ ), nowness of trauma memories (Michael et al. 2005; $r=0.58$ ), negative appraisals of the self, including negative interpretation of PTSD symptoms (Ehlers et al. 1998 b; Dunmore et al. 2001; Halligan et al. 2003; r's =0.43-0.62), and rumination about the trauma (Ehlers et al. $1998 b ; r=0 \cdot 48)$.

Finally, the study included resting heart rate as an easy-to-measure potential biological predictor that could be used in screening programmes. A recent review found that eight out of 10 studies showed that elevated heart rate in the acute trauma phase (measured at varying time points between admission to the emergency department and 1 month afterwards) is associated with later PTSD. Elevated heart rates may be a marker of a generalized fear response in those who are at risk of PTSD, and may reflect the strength of the noradrenergic response to the trauma (Bryant, 2006). However, there was great variability in heart rate levels and the strength of association with subsequent PTSD between studies (Bryant, 2006). Bryant et al. (2000) found that a diagnosis of ASD or a resting heart rate of $>90$ beats/min (measured within 20 days post-trauma) predicted PTSD with high sensitivity (88\%) and specificity 
$(85 \%)$. Heart rate accounted for $4 \%$ of the variance of PTSD severity at follow-up.

The purpose of the present prospective longitudinal study was to compare the predictive power of the ASD diagnosis, the set of seven best predictors from Ozer et al.'s (2003) metaanalysis, the set of four theory-derived cognitive variables, and basal heart rate in the prediction of PTSD at 6 months. The 13 predictors were assessed at 2 weeks after injury in an assault. We investigated which constellation of variables would be most predictive of PTSD at 6 months.

\section{METHOD}

\section{Sample characteristics}

Participants had been injured in an assault and were recruited from consecutive attendees of King's College Hospital's Accident and Emergency (A\&E) Department, London, UK. A total of 1063 assault survivors who attended the A\&E department during the recruitment period (July 2003 to December 2004) were contacted, of whom 389 did not fulfil inclusion criteria and 197 declined to take part. Another 255 were initially interested, but failed to schedule or attend the research session within the designated time period. The remaining 222 assault survivors participated in a diagnostic session at 2 weeks, and 205 of these $(92 \%)$ were interviewed again at 6 months. Exclusion criteria were current psychosis, assault occurring in the context of ongoing domestic violence, and inability to remember the assault (e.g. due to head injury). Assaults were mainly physical $(99 \%)$, and $1 \%$ were sexual assaults. Demographic characteristics are listed in Table 1. The study sample was compared on demographic and assault characteristics with a random sample of identical size, drawn from 2785 assault survivors admitted to the same A\&E department during a period of 1 year. There were no significant differences in age, sex or seriousness of injuries as measured by triage category. However, the study sample comprised more Caucasian participants compared to the random A\&E sample, $\chi^{2}(\mathrm{df}=1)=$ $17 \cdot 88, p<0 \cdot 001,58 \cdot 1 \%$ v. $36 \cdot 9 \% \dagger$.

$\dagger$ The figure of $36.9 \%$ presents an underestimate of the number of Caucasian participants. It is based on A\&E department codes that require the staff to code ethnicity in 80 categories based on country of origin. In practice, the category of 'other' was often used for nonBritish participants regardless of their ethnic background.
Table 1. Demographic, clinical and assault characteristics for participants who completed assessments at both 2 weeks and 6 months $(n=205)$

\begin{tabular}{|c|c|}
\hline Variable & \\
\hline \multicolumn{2}{|l|}{ Sex, $n(\%)$} \\
\hline Male & $140(68 \cdot 0)$ \\
\hline Female & $65(32 \cdot 0)$ \\
\hline Age, mean (S.D.) & $35 \cdot 0(11 \cdot 5)$ \\
\hline \multicolumn{2}{|l|}{ Ethnicity, $n(\%)$} \\
\hline Caucasian & $119(58 \cdot 0)$ \\
\hline Black & $67(32 \cdot 7)$ \\
\hline Other & $19(9 \cdot 3)$ \\
\hline \multicolumn{2}{|l|}{ Socio-economic status ${ }^{\mathrm{a}}, n(\%)$} \\
\hline Very low income ( $£ 5000$ or less) & $59(28 \cdot 8)$ \\
\hline Low income ( $£ 5000-£ 15000)$ & $56(27 \cdot 3)$ \\
\hline Moderate income (£15000-£30000) & $43(21 \cdot 0)$ \\
\hline High income (over $£ 30000$ ) & $35(17 \cdot 1)$ \\
\hline Refused information & $12(5 \cdot 9)$ \\
\hline \multicolumn{2}{|l|}{ Marital status, $n(\%)$} \\
\hline Single & $136(66 \cdot 3)$ \\
\hline Married & $39(19 \cdot 0)$ \\
\hline Divorced/separated & $23(11 \cdot 2)$ \\
\hline Widowed & $2(1 \cdot 0)$ \\
\hline No information & $5(2 \cdot 5)$ \\
\hline Education, mean (s.D.) & $14 \cdot 1(4 \cdot 7)$ \\
\hline \multicolumn{2}{|l|}{ Acute stress disorder at 2 weeks, $n(\%)$} \\
\hline Fulfilled diagnostic criteria & $34(16 \cdot 6)$ \\
\hline \multicolumn{2}{|l|}{$\begin{array}{l}\text { Post-traumatic stress disorder at } \\
6 \text { months, } n(\%)\end{array}$} \\
\hline Fulfilled diagnostic criteria & $49(23 \cdot 9)$ \\
\hline Days since assault, mean (s.D.) & $17 \cdot 5(7 \cdot 65)$ \\
\hline \multicolumn{2}{|l|}{ Number of assailants, $n(\%)$} \\
\hline 1 & $107(52)$ \\
\hline 2 or more & $97(48)$ \\
\hline \multicolumn{2}{|l|}{ Weapon involved, $n(\%)$} \\
\hline Yes & $106(52)$ \\
\hline No & $98(48)$ \\
\hline \multicolumn{2}{|l|}{$\begin{array}{l}\text { Survivor under influence of } \\
\text { alcohol/drugs, } n(\%)\end{array}$} \\
\hline Yes & $87(43)$ \\
\hline No & $117(57)$ \\
\hline
\end{tabular}

S.D., Standard deviation.

Assault characteristics were missing for one participant.

a Combined household income.

Education correlated negatively with PTSD at 6 months $(r=-0.25, p<0 \cdot 001)$ and age correlated positively $(r=0 \cdot 15, p<0 \cdot 05)$. None of the other demographic variables distinguished between participants with and without PTSD at 6 months (all $p$ 's $>0 \cdot 07$ ). With respect to assault characteristics, the PTSD group reported less alcohol or drug consumption during the assault $\left[\chi^{2}(1, n=204)=11 \cdot 71, p=0.001\right]$, but the groups did not differ significantly in other variables (e.g. injury severity, assault duration, and proximity to victims' home). 


\section{Measures}

Diagnostic interviews

ASD and PTSD diagnoses were established with standard structured clinical interviews: the Acute Stress Disorder Scale (Bryant \& Harvey, 2000) and the Structured Clinical Interview for DSM-IV (SCID; First et al. 1996). All interviews were conducted by B.K. under the supervision of A.E. Inter-rater reliability was excellent $(\kappa=0.97$ for ASD, $\kappa=0.82$ for PTSD; based on $n=56$ interviews, two trained raters).

\section{Predictors from Ozer et al.'s (2003)} meta-analysis

Psychological problems prior to trauma. Participants reported whether or not they had had problems with anxiety or depression in the past. This self-report measure correlated significantly with the SCID assessment of a history of major depression $(r=0 \cdot 49, p<0 \cdot 001)$.

Family history of psychological problems. Participants reported whether any of their close family members had ever had a problem with anxiety or depression.

Perceived social support following trauma. A modified subscale from the Crisis Support Scale (CSS; Joseph, 1999) assessed social support soon after the assault $(\alpha=0 \cdot 75)$. Participants rated seven different aspects of social support (e.g. 'Whenever you wanted to talk, how often was there someone willing to listen?') on a scale from 1 (never) to 7 (always). An original item enquiring about personal contact with other trauma survivors was omitted because it did not seem to be relevant for the majority of assault survivors.

Perceived life threat. Participants rated how much they feared for their life during the assault, on a scale from 0 (not at all) to 4 (very strongly). This rating has been shown to predict PTSD (Dunmore et al. 2001; Halligan et al. 2003).

Peritraumatic emotional response. This was measured on a seven-item scale (Halligan et al. 2003; $\alpha=0 \cdot 89)$. Participants rated the extent to which they had experienced the following emotions during the assault: terrified, ashamed, helpless, fearful, guilty, horrified, frightened, each on a scale from 0 (not at all) to 4 (very strongly).

Peritraumatic dissociation. Dissociation during the assault was assessed with the State Dissociation Questionnaire (Murray et al. 2002; $\alpha=0 \cdot 88$ ), a nine-item scale assessing different aspects of dissociation such as derealization, depersonalization, detachment, altered time sense, emotional numbing, and reduction of awareness in surroundings. The scale has been shown to have good reliability and predictive validity in previous studies (e.g. Halligan et al. 2002).

\section{Theory-derived cognitive predictors}

Four more variables were chosen on the basis of earlier studies to each represent one of the four hypothesized cognitive domains specified in Ehlers \& Clark's (2000) model of PTSD. The model states that people with PTSD experience a sense of current threat that arises from two sources: (1) excessively negative appraisals of the trauma and/or its consequences, and (2) certain characteristics of the trauma memory that lead to easy cue-driven retrieval (i.e. unintentional triggering by matching stimuli) of aspects of the trauma memory. These memory characteristics are thought to result from (3) the quality of cognitive processing during the event. Finally, a range of (4) cognitive and behavioural strategies (e.g. rumination, thought suppression, excessive precautions, and ongoing dissociation) that individuals use to control the threat and symptoms are thought to maintain PTSD.

Negative appraisals of the self. Negative appraisals of the self were measured with the Negative Thoughts about the Self subscale of the Posttraumatic Cognitions Inventory (PTCI; 21 items; $\alpha=0.93$; Foa et al. 1999). The scale measures generalized negative appraisals of the trauma and its aftermath (e.g. 'My reactions since the event mean that I am going crazy', 'I have permanently changed for the worse', 'I am a weak person') and has been shown to have good reliability, convergent validity and to discriminate well between traumatized people with and without PTSD (Foa et al. 1999). 
'Nowness' of trauma memories. Trauma memories are thought to be disjointed from other autobiographical memories, leading to a deficit in the awareness that they reflect an experience of the self in the past (Ehlers et al. 2004). Perceived 'nowness' of traumatic memories was measured with the corresponding item from the Assault Memory Questionnaire (Halligan et al. 2003): "When I remember the assault, it is like happening again, here and now'. Self-reported 'nowness' correlates well with interview assessment $(r=0.84$; Hackmann et al. 2004), and the retest reliability is $r=0.68$ (Speckens et al. 2006).

Mental defeat. Mental defeat refers to processing the trauma as a complete loss of personal autonomy and has been shown to predict PTSD in survivors of assault and torture (Dunmore et al. 1999, 2001; Ehlers et al. 2000). The Mental Defeat Scale (Dunmore et al. 1999, 2001; $\alpha=0.90)$ is an 11-item self-report questionnaire. Participants rated the extent to which statements such as 'I no longer felt like a human being' or 'In my mind, I gave up' applied to them at some time during the assault, each on a scale from 0 (not at all) to 4 (very strongly).

Rumination. Rumination about the trauma and its consequences was measured with the eight-item subscale of the Response to Intrusions Questionnaire (Clohessy \& Ehlers, 1999; Murray et al. 2002; $\alpha=0 \cdot 84$ ). Participants rated how often they did things such as 'I think about why the event happened to me' or 'I go over and over the assault', when memories of the assault popped into their mind, each on a scale from 0 (never) to 3 (always). The scale has been shown to have good reliability and predictive validity (Murray et al. 2002; Ehring et al. 2006).

\section{Resting heart rate}

Heart inter-beat intervals were registered with an S810 Polar watch (Polar Electro, Vantaa, Finland) for a period of $3 \mathrm{~min}$, while participants remained seated. Participants were instructed to sit quietly, not to speak and to keep their eyes open. Heart rate data were available for 177 participants $(80 \%)$. The Polar device has been shown to reliably assess inter-beat intervals during rest as well as activity (e.g. Laukkanen \& Virtanen, 1998). None of the participants were taking beta-blockers or other medication affecting the cardiovascular system.

\section{Procedure}

The study was approved by the local ethics committees, and participants gave written consent. Participants completed a research session comprising the completion of questionnaires assessing the psychological predictor variables, heart rate assessment and the ASD Scale (Bryant \& Harvey, 2000) interview. At 6 months, the SCID (First et al. 1996) was conducted over the telephone by the same interviewer. Participants received $£ 50$ as reimbursement for their time.

\section{Statistical analysis}

SPSS version 13.0 (SPSS Inc., Chicago, IL, USA) was used for most analyses; bootstrap analyses were implemented by Stata Statistics and Data Analysis Package version 9.0 (Stata Corporation, College Station, TX, USA). Predictors were $z$-standardized to allow direct comparison of odds ratios (ORs). Association between candidate predictors and PTSD were first investigated with univariate logistic regression analyses. Hierarchical logistic regression analysis tested which of the predictors explained PTSD at 6 months over and above what could be predicted from the ASD diagnosis, by forcing ASD into the equation in the first step and the predictor in the second step. In addition, two multivariate logistic regression analyses tested the predictive power of the variable sets from Ozer et al.'s (2003) meta-analysis and from the cognitive model (including only significant univariate predictors). Finally, a logistic regression analysis of all significant univariate predictors identified the combination of predictors that best predicted PTSD at 6 months; this model determined which variables to add to the model based on the likelihood ratio test. Reliability of univariate results was established by calculating confidence intervals (CIs) for ORs of all predictors with bootstrap resampling (Efron \& Tibshirani, 1986), which involved drawing 1000 random subsamples of the total sample. 
Table 2. Associations of predictors at 2 weeks with PTSD diagnosis at 6 months

\begin{tabular}{|c|c|c|c|c|c|c|c|c|}
\hline \multirow[b]{3}{*}{ Predictor } & & & \multicolumn{3}{|c|}{ Univariate logistic regression } & & & \multirow{3}{*}{$\begin{array}{l}\text { Sign predictor } \\
\text { after controlling } \\
\text { for ASD }\end{array}$} \\
\hline & \multicolumn{2}{|c|}{ Diagnosis at 6 months } & \multirow[b]{2}{*}{$\mathrm{OR}^{\mathrm{a}}$} & \multirow[b]{2}{*}{$95 \% \mathrm{CI}$} & \multirow{2}{*}{$\begin{array}{l}\text { Boot- } \\
\text { strapped } \\
\text { CI }\end{array}$} & \multicolumn{2}{|c|}{ Multiple logistic regression } & \\
\hline & PTSD & No PTSD & & & & $\mathrm{OR}^{\mathrm{a}}$ & $95 \% \mathrm{CI}$ & \\
\hline \multicolumn{6}{|l|}{$\begin{array}{l}\text { Acute stress disorder } \\
\text { ASD diagnosis }\end{array}$} & \multicolumn{3}{|c|}{$R^{2}=0 \cdot 25(95 \%$ CI $0 \cdot 15-0 \cdot 35), \chi^{2}=36 \cdot 89^{* * *}$} \\
\hline ASD diagnosis & & & \multirow[b]{2}{*}{$2 \cdot 50^{* * *}$} & & & \multirow{2}{*}{\multicolumn{2}{|c|}{$1 \cdot 84-3 \cdot 41$}} & \\
\hline $\begin{array}{l}\text { Yes } \\
\text { No }\end{array}$ & 23 & $\begin{array}{r}11 \\
145\end{array}$ & & $1 \cdot 84-3 \cdot 41$ & $1 \cdot 13-2 \cdot 96$ & & & N.A. \\
\hline \multicolumn{6}{|l|}{$\begin{array}{l}\text { Risk factors from the } \\
\text { Ozer } \text { et al. }(2003) \\
\text { meta-analysis }\end{array}$} & \multicolumn{3}{|c|}{$R^{2}=0.37(95 \%$ CI $0.24-0 \cdot 47), \chi^{2}=48 \cdot 22^{* * *}$} \\
\hline \multicolumn{9}{|l|}{ Prior trauma } \\
\hline $\begin{array}{l}\text { Yes } \\
\text { No }\end{array}$ & $\begin{array}{r}46 \\
1\end{array}$ & $\begin{array}{r}142 \\
46\end{array}$ & $1 \cdot 47$ & $0 \cdot 87-2 \cdot 47$ & $0 \cdot 28-1 \cdot 44$ & Not included ${ }^{b}$ & \multicolumn{2}{|r|}{$0 \cdot 225$} \\
\hline \multicolumn{9}{|l|}{$\begin{array}{l}\text { Prior psychological } \\
\text { problems }\end{array}$} \\
\hline $\begin{array}{l}\text { Yes } \\
\text { No }\end{array}$ & $\begin{array}{l}31 \\
16\end{array}$ & $\begin{array}{r}45 \\
107\end{array}$ & $2 \cdot 10^{* * *}$ & $1 \cdot 50-2 \cdot 95$ & $0 \cdot 84-3 \cdot 18$ & $2 \cdot 06^{* *}$ & $1 \cdot 35-3 \cdot 16$ & $0 \cdot 001$ \\
\hline \multicolumn{9}{|l|}{$\begin{array}{l}\text { Family history of } \\
\text { psychological problems }\end{array}$} \\
\hline $\begin{array}{l}\text { Yes } \\
\text { No }\end{array}$ & $\begin{array}{l}14 \\
32\end{array}$ & $\begin{array}{r}37 \\
115\end{array}$ & $1 \cdot 15$ & $0 \cdot 83-1 \cdot 58$ & $0 \cdot 75-2 \cdot 34$ & Not included ${ }^{\mathrm{b}}$ & & $0 \cdot 623$ \\
\hline $\begin{array}{l}\text { Perceived life threat, } \\
\text { mean (s.D.) }\end{array}$ & $2 \cdot 25(1 \cdot 59)$ & $1 \cdot 05(1 \cdot 46)$ & $2 \cdot 12^{* * *}$ & $1 \cdot 52-2 \cdot 96$ & $0 \cdot 78-2 \cdot 27$ & $1 \cdot 22$ & $0 \cdot 75-1 \cdot 98$ & $0 \cdot 006$ \\
\hline $\begin{array}{l}\text { Peritraumatic emotional } \\
\text { response, mean (s.D.) }\end{array}$ & $2 \cdot 61(0 \cdot 96)$ & $1 \cdot 66(1 \cdot 04)$ & $2 \cdot 77 * * *$ & $1 \cdot 85-4 \cdot 14$ & $0 \cdot 83-3 \cdot 06$ & $2 \cdot 43^{* *}$ & $1 \cdot 32-4 \cdot 50$ & $0 \cdot 001$ \\
\hline $\begin{array}{l}\text { Perceived social support, } \\
\text { mean (s.D.) }\end{array}$ & $3 \cdot 35(1 \cdot 34)$ & $3 \cdot 79(1 \cdot 17)$ & $0 \cdot 70^{*}$ & $0 \cdot 50-1 \cdot 00$ & $0 \cdot 29-1 \cdot 40$ & $0.64 *$ & $0 \cdot 42-3 \cdot 16$ & $0 \cdot 112$ \\
\hline $\begin{array}{l}\text { Peritraumatic dissociation, } \\
\text { mean (s.D.) }\end{array}$ & $2 \cdot 24(0 \cdot 94)$ & $1 \cdot 31(1 \cdot 09)$ & $2 \cdot 35^{* * *}$ & $1 \cdot 65-3 \cdot 52$ & $1 \cdot 04-3 \cdot 04$ & $1 \cdot 42$ & $0 \cdot 86-2 \cdot 35$ & $0 \cdot 011$ \\
\hline $\begin{array}{l}\text { Theory-derived cognitive } \\
\text { measures }\end{array}$ & & & & & & $R^{2}=0.50(95 \%$ & CI $0 \cdot 38-0 \cdot 5$ & $9), \chi^{2}=68 \cdot 91^{* * *}$ \\
\hline Mental defeat, mean (S.D.) & $2 \cdot 15(1 \cdot 09)$ & $0.89(0 \cdot 80)$ & $3 \cdot 76^{* * *}$ & $2 \cdot 51-5 \cdot 65$ & $1 \cdot 29-3 \cdot 51$ & 1.74 & $0 \cdot 97-3 \cdot 11$ & $0 \cdot 000$ \\
\hline $\begin{array}{l}\text { Nowness of trauma } \\
\text { memories, mean (s.D.) }\end{array}$ & $2 \cdot 21(1 \cdot 53)$ & $0 \cdot 73(1 \cdot 10)$ & $2 \cdot 89 * * *$ & $1 \cdot 99-4 \cdot 19$ & $1 \cdot 18-4 \cdot 81$ & $1.67 *$ & $1 \cdot 00-2 \cdot 79$ & $0 \cdot 000$ \\
\hline $\begin{array}{l}\text { Negative appraisals of the } \\
\text { self, mean (S.D.) }\end{array}$ & $3.47(1 \cdot 20)$ & $2 \cdot 19(0 \cdot 96)$ & $3 \cdot 18 * * *$ & $2 \cdot 09-4 \cdot 82$ & $1 \cdot 36-4 \cdot 75$ & $1.99 *$ & $1 \cdot 13-3 \cdot 50$ & $0 \cdot 000$ \\
\hline Rumination, mean (s.D.) & $1.79(0 \cdot 60)$ & $1 \cdot 00(0 \cdot 58)$ & $4 \cdot 19 * * *$ & $2 \cdot 52-7 \cdot 01$ & $1 \cdot 16-3 \cdot 26$ & $1.92 *$ & $1 \cdot 04-3 \cdot 56$ & $0 \cdot 000$ \\
\hline Biological measure & & & & & & $R^{2}=0.04(95$ & ${ }_{0} \mathrm{CI} 0 \cdot 00-0$ & 11), $\chi^{2}=4 \cdot 90^{*}$ \\
\hline $\begin{array}{l}\text { Resting heart rate, } \\
\text { mean (s.D.) }\end{array}$ & $71 \cdot 80(12 \cdot 35)$ & $67 \cdot 10(10 \cdot 80)$ & $1 \cdot 50^{*}$ & $1 \cdot 04-2 \cdot 15$ & $0 \cdot 77-2 \cdot 99$ & $1 \cdot 50^{*}$ & $1 \cdot 04-2 \cdot 15$ & $0 \cdot 049$ \\
\hline
\end{tabular}

PTSD, Post-traumatic stress disorder; ASD, acute stress disorder; s.D., standard deviation; N.A., not applicable; CI, confidence interval

${ }^{\text {a }}$ Predictors are $z$-standardized to make odds ratios comparable; ${ }^{\mathrm{b}}$ as non-significant in univariate analysis.

Questionnaire ranges: mental defeat $0-4$, nowness of trauma memories $0-4$, negative appraisals about the self $1-7$, rumination $0-4$, perceived life threat $0-4$, perceived support $1-7$, peritraumatic dissociation $0-4$.

$* * * \quad p<0 \cdot 001, * * \quad p<0 \cdot 01, * p<0 \cdot 05$.

\section{RESULTS}

\section{ASD and PTSD prevalence}

At 2 weeks, $17 \%$ of the participants $(n=37 / 222)$ met diagnostic criteria for ASD, and at 6 months, $24 \% \quad(n=49 / 205)$ met diagnostic criteria for PTSD.

\section{Early predictors of chronic PTSD}

Table 2 shows the associations between the predictors assessed at 2 weeks and PTSD at
6 months. Most univariate associations were significant. Participants with ASD were at increased risk for PTSD at 6 months compared to those without ASD (non-transformed OR $11 \cdot 7, \phi=0 \cdot 46$ ). Table 2 shows that although the majority of participants with ASD went on to develop chronic PTSD (68\%), ASD had low sensitivity $(47 \%)$ in predicting PTSD.

Most of the predictors derived from Ozer et al.'s (2003) meta-analysis were significantly associated with a greater PTSD risk (prior 
psychological problems, less post-trauma social support, greater perceived threat to life, peritraumatic emotional responses and dissociation during the assault). Associations with prior trauma (non-transformed OR $4 \cdot 54,95 \%$ CI $0.58-35.45, \phi=0.11)$ and family history of psychological problems (non-transformed OR $1 \cdot 36,95 \%$ CI $0.66-2 \cdot 82, \phi=0.06)$ did not reach significance. All theory-derived cognitive variables (mental defeat, nowness of memories, negative appraisals of the self, and rumination about the trauma) and resting heart rate predicted PTSD. Bootstrap analyses for 1000 subsamples showed that ORs and CIs replicated well. Table 2 also shows which of the variables predicted PTSD at 6 months over and above what could be predicted from an ASD diagnosis at 2 weeks. These were the four theory-derived cognitive variables, prior psychological problems, perceived life threat, peritraumatic emotional response and dissociation, and resting heart rate.

Next, we compared the predictive power of the sets of variables under investigation (Table 2). The theory-derived cognitive variables explained $50 \%$ of the variance (sensitivity $0 \cdot 60$, specificity $0.95,88 \%$ correct classifications). CIs indicated that the strength of the prediction was significantly larger than the $25 \%$ explained by an ASD diagnosis (sensitivity 0.47 , specificity $0.93,82 \%$ correct classifications), and the $4 \%$ explained by resting heart rate at 2 weeks (sensitivity $0 \cdot 00$, specificity $1 \cdot 00$ ). The established predictors identified in Ozer et al.'s (2003) meta-analysis explained $37 \%$ of the variance (sensitivity $0 \cdot 44$, specificity $0.95,85 \%$ correct classifications), which was not significantly different from the predictive power of the ASD diagnosis.

When all significant predictors were considered in an overall multiple logistic regression analysis, mental defeat (OR 2.07, $p=0.014$, $95 \%$ CI $1 \cdot 16-3 \cdot 70)$, rumination about the trauma (OR 2.99, $p=0 \cdot 002,95 \%$ CI 1.50-5.96) and prior psychological problems (OR 1.95, $p=0 \cdot 014,95 \%$ CI $1 \cdot 14-3 \cdot 31)$ were chosen as the best combination of predictors by the forward likelihood ratio test $\left(\chi^{2}=47 \cdot 37, p=0.000\right)$. Together, the three variables explained $47 \%$ of the variance (sensitivity 0.57 , specificity 0.96 ) and classified $88 \%$ of the cases correctly into PTSD and non-PTSD status. The Hosmer and
Lemeshow goodness-of-fit test showed that the model fit the data well $\left(\chi^{2}=9 \cdot 86, p=0 \cdot 275\right)$. Not selected were ASD (after last step $p=0 \cdot 184$ ), perceived threat to life $(p=0 \cdot 452)$, peritraumatic dissociation $(p=0.941)$, peritraumatic emotional response $(p=0.695)$, nowness of trauma memories $(p=0 \cdot 138)$, negative appraisals about the self $(p=0.589)$ and resting heart rate $(p=0 \cdot 828)$.

\section{DISCUSSION}

This prospective longitudinal study found that $17 \%$ of 222 injured assault survivors met diagnostic criteria for ASD at 2 weeks after the event, and at 6 months, $24 \%$ had PTSD. These prevalences are similar to those reported in other studies of assault survivors (e.g. Harvey \& Bryant, 1998; Brewin et al. 1999). While the majority of participants with ASD went on to develop chronic PTSD (68\%), ASD had low sensitivity $(47 \%)$ in predicting PTSD, again in accord with previous studies (Brewin et al. 1999; Creamer et al. 2004; Elklit \& Brink, 2004; see McNally et al. 2003 for a review). One of the reasons for the low sensitivity of ASD may be that not all assault survivors at risk for PTSD may have had the three dissociative symptoms required for a diagnosis. Overall, the usefulness of ASD as a criterion for identifying people at risk of PTSD was limited.

This raises the question of whether there are other ways of identifying people at risk for chronic PTSD (e.g. Shalev et al. 1997; Brewin et al. 2002). The present study tested three groups of candidate predictors of PTSD identified in previous research, namely the seven best established predictors of PTSD according to the meta-analysis of Ozer et al. (2003), four predictors derived from a cognitive model of PTSD (Ehlers \& Clark, 2000), and resting heart rate as a candidate biological predictor. In line with previous findings, nearly all of these variables predicted PTSD at 6 months (Ehlers et al. 1998 b; Brewin et al. 2000; Bryant et al. 2000; Dunmore et al. 2001; Murray et al. 2002; Halligan et al. 2003; Ozer et al. 2003). The results extend previous findings in several ways. (1) They demonstrated that the predictors not only are associated with concurrent PTSD but also predict chronic PTSD prospectively; this strengthens Ozer et al.'s (2003) findings, which were 
based largely on cross-sectional studies. (2) The variables were predictive even when assessed 2 weeks after the trauma, which extends the results of previous prospective longitudinal studies where the initial assessment took place later (e.g. Dunmore et al. 2001). (3) The study allowed a direct comparison of the strength of the prediction of different sets of variables suggested as relevant in the literature. (4) Recruitment from an A\&E department ensured a sample that was representative in terms of the severity of assaults and most other demographic characteristics.

Overall, the results replicated well those of the Ozer et al. (2003) meta-analysis. As in the metaanalysis, peritraumatic variables (peritraumatic dissociation and emotions, perceived life threat) and social support tended to be stronger predictors than pre-trauma characteristics (see also Brewin et al. 2000). The finding that the relationships between prior trauma and a family history of psychological problems and PTSD did not reach significance in this study should not be overinterpreted. Given the modest PTSD rate in the sample, our study had low power for detecting very small effect sizes. Restrictions in range may have played a role as the majority of the participants reported prior trauma. However, it is also possible that the type of trauma or timing of assessment plays a role in the strength of the relationship of these variables with PTSD, as other studies of singleevent trauma have also failed to establish a relationship between family history and PTSD (Blanchard \& Hickling, 2004) and as Ozer et al. (2003) identified three previous studies of recent trauma survivors ( $\leqslant 4$ months), all of which found no relationship between trauma history and PTSD ( $r$ 's $=0 \cdot 00-0 \cdot 03)$.

The set of predictors from the Ozer et al. (2003) meta-analysis did not significantly predict chronic PTSD better than the ASD diagnosis. A possible explanation may be that these variables mainly predict the onset of symptoms, but are less useful for the prediction of longterm outcome as maintaining factors are not included (e.g. Ehlers \& Steil, 1995). By contrast, the theory-derived cognitive factors each predicted PTSD at 6 months over and above what can be predicted from an ASD diagnosis at 2 weeks, and together explained more variance than ASD. This finding may reflect the fact that PTSD symptoms show substantial natural recovery in the first months after trauma (e.g. Rothbaum et al. 1992; Kessler et al. 1995), and factors that impede recovery and maintain PTSD symptoms may therefore be of particular interest in predicting chronic PTSD (e.g. Ehlers \& Steil, 1995; Ehlers \& Clark, 2000).

The logistic regression analysis that considered all candidate predictors simultaneously identified a combination of two of such theoryderived maintaining variables (mental defeat, rumination) and a vulnerability variable (psychological problems prior to the assault) as the best predictor set. This suggests that the combination of vulnerability and maintaining factors may provide the best prediction of chronic PTSD. The combination of these three predictors predicted diagnostic status at 6 months correctly in $88 \%$ of the cases. Together, the three variables explained almost half of the variance in PTSD diagnosis at 6 months, compared to $25 \%$ of explained variance by the ASD diagnosis.

In line with previous research, resting heart rate at 2 weeks predicted PTSD at 6 months, but only explained a small proportion of the variance. Bryant (2006) proposed multiple pathways to PTSD development, some of which are characterized by elevated and others by lowered heart rate levels (alongside dissociative responses). Such differences in response pattern would be consistent with the present results, but limit the usefulness of basal heart rate as a way of early screening for risk of chronic PTSD. Heart rate may be more predictive if it is assessed sooner after the trauma, although the currently available data show great variation for the predictive power of such early assessments (Bryant, 2006). It is also possible that the participants' heart rate may have been influenced by memories triggered by the questionnaires that were part of the research session, although such responses would have been expected to increase rather than decrease the relationship between heart rate and PTSD.

The study had strengths and limitations. Among the strength are the prospective longitudinal design, the relatively large number of participants, the excellent follow-up rate, the use of reliable structured interviews to establish diagnoses, the replication of the results in bootstrapping analyses, and the early initial 
assessment. Nevertheless, further research will need to establish how well the present results generalize to other populations with different PTSD rates and other forms of trauma before the results are applied to clinical practice. The sample showed a moderate PTSD rate of $24 \%$ at follow-up, and had low power to detect very small effect sizes. Thirteen potential predictors were considered, which raises the possibility of false positive associations. However, all of the predictors had been shown to be associated with PTSD risk in previous studies, and the present sample replicated earlier results well and showed good replication in bootstrapping analyses. Although our analyses indicated that the sample was fairly representative of assault survivors attending the A\&E department, it comprised relatively fewer people of ethnic minorities compared to the population of assault survivors treated at this hospital (nevertheless, the $42 \%$ exceeded the $24 \%$ ethnic minorities living in London according to the 2001 Census). The concept of mental defeat, one of the strongest predictors in this study, was developed with survivors of interpersonal violence such as assault and torture (e.g. Dunmore et al. 1999, 2001; Ehlers et al. 1998a, 2000), and other predictors may be more relevant for survivors of other traumas such as accidents or natural disaster. A further possible limitation was that PTSD diagnoses at 6 months were based on a diagnostic interview conducted over the telephone, rather than a face-to-face diagnostic interview. It may be argued that telephone interviews make participants somewhat less forthcoming in providing information about their symptoms than face-to-face interviews. However, the interviewer had already established a relationship with the participants at the first assessment, which makes it unlikely that participants withheld information from her later. Finally, personal and family history of problems with anxiety or depression was assessed with simple self-report questions, and more sophisticated assessments may have given different results.

In conclusion, this study found that PTSD at 6 months after injury in an assault can be predicted from early assessment at 2 weeks. A set of four theory-derived cognitive variables predicted PTSD better than the ASD diagnosis. Logistic regression analysis suggested that the combination of mental defeat, rumination and a history of problems with anxiety or depression predicted PTSD best. These concepts can be measured with only 20 self-report questions. However, it remains to be tested how the three selected scales perform on their own, as they were selected from a larger group of 11 significant predictors in this study. If replicated, our results suggest that assault survivors are at heightened PTSD risk if they report mental defeat at the time of the event, if they ruminate about the trauma, and if they report prior problems with depression or anxiety. Early assessment of these predictors appears straightforward and may be useful for screening programmes in general practice or communities affected by trauma. They may help to identify those trauma survivors who are most likely to develop PTSD and who would benefit from early intervention. Putting the experience of mental defeat in perspective and reducing rumination appear to be promising targets for such interventions.

\section{ACKNOWLEDGEMENTS}

This study was funded by a grant from the Psychiatry Research Trust and a Wellcome Trust Principal Research Fellowship to Anke Ehlers. We thank Thomas Ehring, Silke Frank, Inga Boellinghaus, Emma Briddon, Anke Weidmann, Ines Sengstock, Johanna Hissbach, Jennifer Baumeister, Stephanie Spengler and the staff of King's College Accident and Emergency Department for their help.

\section{DECLARATION OF INTEREST}

None.

\section{REFERENCES}

APA (1994). Diagnostic and Statistical Manual of Mental Disorders (4th edn). American Psychiatric Association: Washington, DC.

Bisson, J. I. \& Cohen, J. A. (2006). Disseminating early interventions following trauma. Journal of Traumatic Stress 19, 583-595.

Blanchard, E. B. \& Hickling, E. J. (2004). After the Crash: Psychological Assessment and Treatment of Survivors of Motor Vehicle Accidents (2nd edn). American Psychiatric Association: Washington, DC.

Brewin, C. R., Andrews, B., Rose, S. \& Kirk, M. (1999). Acute stress disorder and posttraumatic stress disorder in victims of violent crime. American Journal of Psychiatry 156, 360-366.

Brewin, C. R., Andrews, B. \& Valentine, J. D. (2000). Meta-analysis of risk factors for posttraumatic stress disorder in traumaexposed adults. Journal of Consulting and Clinical Psychology $\mathbf{6 8}$, 748-766. 
Brewin, C. R., Rose, S., Andrews, B., Green, J., Tata, P., McEvedy, C., Turner, S. \& Foa, E. B. (2002). Brief screening instrument for post-traumatic stress disorder. British Journal of Psychiatry 181, $158-162$.

Bryant, R. A. (2003). Early predictors of posttraumatic stress disorder. Biological Psychiatry 53, 789-795.

Bryant, R. A. (2006). Longitudinal psychophysiological studies of heart rate: mediating effects and implications for treatment. Annals of the New York Academy of Sciences 1071, 19-26.

Bryant, R. A. \& Harvey, A. G. (2000). Acute Stress Disorder: A Handbook of Theory, Assessment, and Treatment. American Psychological Association: Washington, DC.

Bryant, R. A., Harvey, A. G., Guthrie, R. M. \& Moulds, M. L. (2000). A prospective study of psychophysiological arousal, acute stress disorder, and posttraumatic stress disorder. Journal of Abnormal Psychology 109, 341-344.

Clohessy, S. \& Ehlers, A. (1999). PTSD symptoms, response to intrusive memories and coping in ambulance service workers. British Journal of Clinical Psychology 38, 251-265.

Creamer, M., O'Donnell, M. L. \& Pattison, P. (2004). The relationship between acute stress disorder and posttraumatic stress disorder in severely injured trauma survivors. Behaviour Research and Therapy 43, 315-328.

Dunmore, E., Clark, D. M. \& Ehlers, A. (1999). Cognitive factors involved in the onset and maintenance of posttraumatic stress disorder (PTSD) after physical or sexual assault. Behaviour Research and Therapy 37, 809-829.

Dunmore, E., Clark, D. M. \& Ehlers, A. (2001). A prospective investigation of the role of cognitive factors in persistent posttraumatic stress disorder (PTSD) after physical or sexual assault. Behaviour Research and Therapy 39, 1063-1084.

Efron, B. \& Tibshirani, R. (1986). Bootstrap methods for standard errors, confidence intervals and other measures of statistical accuracy. Statistical Science 1, 54-77.

Ehlers, A. \& Clark, D. M. (2000). A cognitive model of posttraumatic stress disorder. Behaviour Research and Therapy 38, 319-345.

Ehlers, A., Clark, D. M., Dunmore, E., Jaycox, L., Meadows, E. \& Foa, E. B. (1998 a). Predicting response to exposure treatment in PTSD: the role of mental defeat and alienation. Journal of Traumatic Stress 11, 457-471.

Ehlers, A., Hackmann, A. \& Michael, T. (2004). Intrusive reexperiencing in post-traumatic stress disorder: phenomenology, theory, and therapy. Memory 12, 403-415.

Ehlers, A., Maercker, A. \& Boos, A. (2000). Posttraumatic stress disorder following political imprisonment: the role of mental defeat, alienation, and perceived permanent change. Journal of Abnormal Psychology 109, 45-55.

Ehlers, A., Mayou, R. A. \& Bryant, B. (1998b). Psychological predictors of chronic posttraumatic stress disorder after motor vehicle accidents. Journal of Abnormal Psychology 107, 508-519.

Ehlers, A., Mayou, R. A. \& Bryant, B. (2003). Cognitive predictors of posttraumatic stress disorder in children: results of a prospective longitudinal study. Behaviour Research and Therapy 41, 1-10.

Ehlers, A. \& Steil, R. (1995). Maintenance of intrusive memories in posttraumatic stress disorder: a cognitive approach. Behavioural and Cognitive Psychotherapy 23, 217-249.

Ehring, T., Ehlers, A. \& Glucksman, E. (2006). Contribution of cognitive factors to the prediction of post-traumatic stress disorder, phobia and depression after motor vehicle accidents. Behaviour Research and Therapy 44, 1699-1716.

Elklit, A. \& Brink, O. (2004). Acute stress disorder as a predictor of post-traumatic stress disorder in physical assault victims. Journal of Interpersonal Violence 19, 709-726.

First, M. B., Spitzer, R. L., Gibbon, M. \& Williams, J. B. W. (1996). Structured Clinical Interview for DSM-IV Axis I Disorders. American Psychiatric Press: Washington, DC.

Foa, E. B., Ehlers, A., Clark, D. M., Tolin, D. F. \& Orsillo, S. M. (1999). The Posttraumatic Cognitions Inventory (PTCI): development and validation. Psychological Assessment 11, 303314.
Galea, S., Ahern, J., Resnick, H., Kilpatrick, D., Bucuvalas, M., Gold, J. \& Vlahov, D. (2002). Psychological sequelae of the September 11 terrorist attacks in New York City. New England Journal of Medicine 346, 982-987.

Hackmann, A., Ehlers, A., Speckens, A. \& Clark, D. M. (2004). Characteristics and content of intrusive memories in PTSD and their changes with treatment. Journal of Traumatic Stress 17, $231-240$

Halligan, S. L., Clark, D. M. \& Ehlers, A. (2002). Cognitive processing, memory, and the development of PTSD symptoms: two experimental analogue studies. Journal of Behavior Therapy and Experimental Psychiatry 33, 73-89.

Halligan, S. L., Michael, T., Clark, D. M. \& Ehlers, A. (2003). Posttraumatic stress disorder following assault: the role of cognitive processing, trauma memory, and appraisals. Journal of Consulting and Clinical Psychology 71, 419-431.

Harvey, A. G. \& Bryant, R. A. (1998). The relationship between acute stress disorder and posttraumatic stress disorder: a prospective evaluation of motor vehicle accident survivors. Journal of Consulting and Clinical Psychology 66, 507-512.

Harvey, A. G. \& Bryant, R. A. (2000). A two-year prospective evaluation of the relationship between acute stress disorder and posttraumatic stress disorder following mild traumatic brain injury. American Journal of Psychiatry 157, 626628.

Joseph, S. (1999). Social support and mental health following trauma. In Post-traumatic Stress Disorder: Concepts and Therapy (ed. W. Yule), pp. 71-91. Wiley: Chichester.

Kessler, R. C., Sonnega, A., Bromet, E., Hughes, M. \& Nelson, C. B. (1995). Posttraumatic stress disorder in the National Comorbidity Survey. Archives of General Psychiatry 52, 1048-1060.

Laukkanen, R. M. T. \& Virtanen, P. (1998). Heart rate monitors: state of the art. Journal of Sports Sciences 16, 3-7.

Marshall, R. D., Spitzer, R. \& Liebowitz, M. R. (1999). Review and critique of the new DSM-IV diagnosis of acute stress disorder. American Journal of Psychiatry 156, 1677-1685.

Mayou, R. A., Ehlers, A. \& Bryant, B. (2002). Posttraumatic stress disorder after motor vehicle accidents: 3-year follow-up of a prospective longitudinal study. Behaviour Research and Therapy 40, 665-675.

McNally, R. J., Bryant, R. A. \& Ehlers, A. (2003). Does early psychological intervention promote recovery from posttraumatic stress? Psychological Science in the Public Interest 4, 45-79.

Michael, T., Ehlers, A., Halligan, S. \& Clark, D. M. (2005). Unwanted memories of assault: what intrusion characteristics predict PTSD? Behaviour Research and Therapy 43, 613628.

Murray, J., Ehlers, A. \& Mayou, R. A. (2002). Dissociation and post-traumatic stress disorder: two prospective studies of road traffic accident survivors. British Journal of Psychiatry 180, 363 368.

NCCMH (2005). Post-traumatic stress disorder: the management of PTSD in adults and children in primary and secondary care. National Collaborating Centre for Mental Health. National Institute for Clinical Excellence (NICE): London, UK.

Ozer, E. J., Best, S. R., Lipsey, T. L. \& Weiss, D. S. (2003) Predictors of posttraumatic stress disorder and symptoms in adults: a meta-analysis. Psychological Bulletin 129, 52-73.

Rose, S., Bisson, J., Churchill, R. \& Wesseley, S. (2002). Psychological debriefing for preventing posttraumatic stress disorder. The Cochrane Database of Systematic Reviews. Issue 2. Article No.: CD00560.

Rothbaum, B. O., Foa, E. B., Riggs, D. S., Murdock, T. \& Walsh, W. (1992). A prospective examination of posttraumatic stress disorder in rape victims. Journal of Traumatic Stress $\mathbf{5}$, 455-475.

Rubin, G. J., Brewin, C. R., Greenberg, N., Simpson, J. \& Wessely, S. (2005). Psychological and behavioural reactions to the bombings in London on 7 July 2005: cross sectional survey of a representative sample of Londoners. British Medical Journal 331, 606. 
Schnyder, U., Moergli, H., Klaghofer, R. \& Buddeberg, C. (2001) Incidence and prediction of posttraumatic stress disorder symptoms in severely injured accident victims. American Journal of Psychiatry 158, 594-599.

Shalev, A. Y. \& Freedman, S. (2005). PTSD following terrorist attacks: a prospective evaluation. American Journal of Psychiatry 170, 558-564

Shalev, A. Y., Freedman, S., Adessky, R. \& Watson, P. (2006). Who needs care, who wants care, who is helped by early intervention: 5600 trauma survivors' results. Abstract no. 159877. In
Symposium at the 22nd Annual Meeting of the International Society for Traumatic Stress Studies, Hollywood, CA, USA

Shalev, A. Y., Freedman, S., Peri, T., Brandes, D. \& Sahar, T. (1997).

Predicting PTSD in trauma survivors: prospective evaluation of self-report and clinician-administered instruments. British Journal of Psychiatry 170, 558-564.

Speckens, A. E., Ehlers, A., Hackmann, A. \& Clark, D. M. (2006)

Changes in intrusive memories associated with imaginal reliving in posttraumatic stress disorder. Journal of Anxiety Disorders 20 , 328-341. 